\title{
Comparison of Special Education Services In Saudi Arabia and Thailand
}

\author{
Yahya D. Alshehri
}

Ph.D in Special Education

\section{Abstract}

7 he world is growing more connected through technology and, with that connection, it is becoming more important to be aware of special education services around the world. In Saudi Arabia and Thailand, special education has seen many reforms in the past century. It wasn't until the mid to late 1900s that special education started gaining traction in both nations. Special education is present and necessary in countries around the world. Different cultural perceptions change how societies treat students with special needs. It is important to be aware of the way diversity effects special education in Saudi Arabia, Thailand, and in every nation. This session will present the data collected from various studies and documents regarding special education services and the impact of culture, finances, and availability of schools and trained educators in two different countries: Saudi Arabia and Thailand. Issues in the history and current climate of special education in these countries will be examined.

Keywords: Special Education, Services, Comparison

\section{Introduction}

As the world becomes more connected, it is important to learn about the educational practices of every nation. People from different nations are exchanging culture and ideas, and this gives people the chance to share knowledge to improve societies. In this paper we will describe special education services and the impact of culture, finances, and availability of school and trained educators in two different countries: Saudi Arabia and Thailand. Knowing about special education in these two countries can help outsiders understand the culture and help people living within the 
country to work to improve their attitudes and actions towards people with special needs, as well as move towards more reform of the special education system.

General Summary of Special Education Services in Saudi Arabia and Thailand

Special education in Saudi Arabia is a fairly new system in the nation. The year 1958 was the first year people with disabilities in Saudi Arabia received any type of special education. At that point, special education services were limited to some students who were blind; however, most students with special needs remained in the care of their parents. By 1972, the first institutes for deaf students and students with learning disabilities were founded and in 1987 the first legislation was passed regarding people with disabilities. This legislation, The Legislation of Disability, guarantees equal rights for individuals with disabilities and describes the special education services that are to be available.

Since these first moves in special education, Saudi Arabia has come a long way - individuals with the following special needs are now receiving services through the government: visual impairment, hearing impairment, intellectual disability, autism, and multiple disabilities. There are currently 1,136 institutes for males with disabilities, 567 institutes for females with disabilities, 3,555 classes in regular schools for males with disabilities, and 1,796 classes in regular schools for females with disabilities (Alnahdi, 2014). Even with all the advancements being made, many still see a need for improved services throughout the country. 
In the early days of its history, education in Thailand evolved around temples and royal courts. Buddhist monks gave basic education to boys in classes set within the temple compound. Children of the royal household and noble families were educated at royal courts. The rest of Thai society consisted of farmers, who at that time didn't require literacy. During the reign of King Rama V (18631910 A.D.), the country's bureaucracy increased and there was an increased need for educated people. With the issue in 1898 of the Education Proclamation, the Thai educational system was modernized and made accessible to all people (Hill \& Sukbanpant, 2013).

According to Hill and Sukbunpant (2013), Thailand made education mandatory as a move in a positive direction in providing special education services to children with disabilities. Monitoring of compliance with disability law and negative attitudes toward individuals with disabilities, though, continue to impede enforcement of the law, distribution of resources, family involvement, and access to individualized education programs and inclusion of students with disabilities.

Children with disabilities were originally seen as an indicator that the family might have committed some sin in the past (Driedger, 1989). Persons with disabilities were stigmatized and considered to be useless and worthless, with no future. Because of this perception, Thai children with disabilities were kept at home and were denied their right in education. Even with the compulsory educational act in 1935, the Ministry of Education allowed a child to stay at home because of his/her disability condition (Sukbunpant, Shiraishi, \& Kuroda, 2004). 
According to Thirajit (2000), in 1939, Genevieve Caulfield, a blind American teacher, provided initial leadership in Thai special education. She was the first person who taught children with visual impairments to live as independent, productive members of society. Caulfield and her friends established the Bangkok School for the Blind, and the Foundation for the Blind under the patronage of Her Majesty the Queen (as cited in Hill \& Sukbanpant, 2013).

It is believed that special education in Thailand was officially organized from that time. Since then, special education has developed gradually. In 1962, children with visual impairments were first allowed to study in the regular school. Children with hearing impairments were the second group in 1984. The Bureau of Special Education Administration, Office of Basic Education Commission is the main agency responsible for the provision of education for children with disabilities (Hill, \& Sukbunpant, 2013). The government of Thailand has historically provided a limited number of educational opportunities for individuals with disabilities, but has recently demonstrated movement toward a more comprehensive educational system. The educational policy has not only begun to expand the incorporation of services for children with disabilities, but also has introduced efforts to include children with disabilities in regular education classrooms (Carter, 2006).

Today, each region of Thailand has a special school for students with disabilities. There has been a broad promotion for these children to study with children without disabilities in the regular schools as much as possible. Because of this, since 1995 at least one public school in 
each of the 76 provinces has a mainstream class for these children (Chonlatanon, 1995).

Since each country has special education services in place along with a move by the government to enact disability legislation, a review of issues that might impact the success of the delivery of special education services in each country was reviewed. Based on a review of published materials about the success or issues with special education service delivery in both Saudi Arabia and Thailand, three possible areas of concern that impact and might impede further advancement were identified. These three areas are financial issues/support; availability of trained educators and appropriate classrooms or schools; and the culture of the society with its own belief systems concerning disability. Each of these issues/areas of concern will be discussed in each of these countries.

\section{Financial Issues/Support}

The first area that was identified as impacting the successful delivery of services was the amount of financial support that is provided by the government. In Saudi Arabia, the government pays for all forms of education. The Ministry of Education in Saudi Arabia is responsible for providing free, appropriate education for all students, including students with disabilities and special needs. The Disability Code, passed in 2000, promises access to free medical, psychological, social, educational, and rehabilitation services through public agencies (Alquraini, 2011). Many of the public institutions meet students' needs with more than education - they provide shelter, food, and financial aid (Alquraini, 2012). 
Even so, knowing that education and related services are available through and provided by the government does not tell us the extent or quality of those services. For example, after elementary and middle school, not many programs are available for special education and the programs that do exist lack related services, such as specialists like therapists and language coaches (Alquraini, 2011). The middle schools and high schools also lack transitional services for students with special needs. Although the middle schools and high schools both include vocational training, with $44 \%$ of students' time spent in that training, independence and adulthood skills are not properly addressed with the vocational training programs. The educational system relies on the financial support of the government, which can fluctuate depending on current events, such as levels of exports for the country. Recently some special education services have been improving as oil prices and sales have gone up (Alnahdi, 2014) but with the decrease in the price of oil there is concern that this improvement may not continue.

Until 1939, the country of Thailand was known as Siam, with the current formal name being the Kingdom of Thailand. Thailand is comprised of 76 provinces that are ruled by a constitutional monarchy. Thailand is the only Southeast Asian country never to have been colonized by a European empire. The Thai economy remains largely export driven with exports accounting for $60 \%$ of an approximate Gross Domestic Product (GDP). Thailand's exports are worth approximately USD 180 billion per annum, and primarily consist of agricultural products, textiles, rubber, automobiles, jewelry, computers and electronic appliances. With the Asian Financial Crisis 
between 1997-1998, Thailand encountered a slow economy, but full recovery occurred in a short period of time. Then in December 2004, Thailand's economy was negatively impacted by the Tsunami disaster. The tsunami resulted in approximately 8,500 deaths and substantial property destruction in the southern provinces (Carter, 2006). Eventually, Thailand is fairly resilient although several crises in recent years have dampened the growth of the economy. Thailand is an economically developed nation with the seventh lowest unemployment rate in the world and $10 \%$ of the population living below the poverty (Tourism Authority of Thailand, 2015).

Regarding national strategies and priorities in education, Thai government's top priory is to develop quality and standards in primary and secondary education. Basic education in Thailand extends from grades 1-12. Primary education is currently administered and combined with secondary education as part of basic education after the major educational reforms in Thailand in 1999 ("Education System Profiles", n.d.). At the local level, public primary schools fall under the authority of Educational Service Areas (ESAs) and the Office of the Basic Education Commission (OBEC) at the Ministry level. Education is mainly financed by the national budget although Local Administration Offices (LAOs) are encouraged to mobilize local resources for education. Since 2002, The National Education Act (NEA) obligated the state to provide general subsidies based on per-student expenditures for basic 12-year education. The funds were allocated directly to schools through Educational Service Areas (ESAs) in block grants. The NEA set the framework for decentralization of authority over curricula and 
spending to local authorities in order to make education more responsive to local needs. (UNESCO, 2011).

The financial sources of education are from government (central and local), private (household, business) and transfer and donation from aboard (ROW). The education budget to the gross domestic product (GDP) is about $4 \%$. The government, private sectors and the nongovernmental organization (NGOs) are the financing agencies allocating educational resources to educational service providers such as public schools, private schools, service agents, and household ("Thailand's National Education Accounts (NEA)", n.d.)

\section{Schools/Trained Educators}

The second area of possible impact is the ability of the schools to provide appropriate diagnosis for children with disabilities and subsequent classes. In order for this to occur, educators who are trained in assessing and educating individuals with disabilities are essential. In Saudi Arabia one of the first issues with special education in the schools is diagnosing the students for identification of disability and subsequent placement in appropriate schools or classes. There are problems with assessments of students entering special education programs as students are diagnosed without a team-based approach, mostly through IQ tests only and, sometimes, through teacher observations (Alquraini, 2012). In fact, $73 \%$ of special education programs and institutes rely only on IQ tests for the diagnosis of intellectual disability. Part of the reason for this is that there's a shortage of specialists to oversee the testing and eligibility process (Alnahdi, 2014). Without a team-based approach and multiple testing platforms, some 
aspects of a student's abilities or disabilities may be overlooked or incorrectly diagnosed.

The movement towards inclusive education has increased in the country. Saudi Arabia leads in integration for the Middle East, with students with mild disabilities now being included in many public schools. $90 \%$ of males and $65 \%$ of females with mild disabilities are now in regular schools. Students in these inclusive classrooms are not truly "included" though - they are often segregated into special groups and not interacting with typically developing (TD) peers. Within the inclusive classroom students are kept in groups with other students with disabilities, often missing classroom activities and do not interact with their typically developing peers. In a truly inclusive setting, the students with disabilities would be given the opportunity to interact with their typically developing peers in daily activities, opening them up to social situations and learning moments.

According to Alqurahdi's (2014) report general education teachers do not welcome special education students and claim they are the responsible for special education teachers. These special education teachers say they've even experienced negative attitudes from the general teachers and have been excluded from the general classrooms. In addition, students with severe disabilities are still educated in segregated special education institutions (Alquraini, 2011). These two situations of exclusion may prohibit students with special needs from improving their social and academic skills without access to typically developing peers. 
The Regulations of Special Education Programs and Institutions (RSEPI) of 2001, modeled after U.S. policies, specify how schools must provide education. They also describe individualized education plans, or IEPs (Alquraini, 2012). All students with special needs are supposed to have IEPs, however currently IEPs do not typically match the individual needs of the students; as they are based on general standards. Unfortunately, classrooms are divided into two groups based on student abilities and needs, with each group having an education plan. Although most of these teachers have a bachelor's degree in special education, they lack help from teacher's assistants (Alnahdi, 2014). Additionally, special education teachers are responsible for as many as 15 students each, so IEPs can be difficult to manage (Alquraini, 2011). IEPs require constant, involved attention in order to be properly followed and to ensure that the students are receiving benefit. Each student has an individual plan, which means he or she has individualized lessons and goals for each day. The ability of one teacher, even one with extensive training and experience, to coordinate separate lessons and other goals for multiple students is questionable.

In Thailand, the existence of special education services has been evident for several years but is currently still expanding and attempts are being made to train qualified individuals to provide educational services. Over the past ten years, the educational policy within Thailand has addressed issues regarding children with disabilities and appears to have moved rather quickly to a more inclusive practice toward individuals with disabilities. The rather rapid pace at which these policies have been implemented appears to have resulted in some difficulties associated 
with the provision of qualified educators, provision of appropriate services, and overcoming outdated practices (Carter, 2006).

Amatyakul, Tammasaeng, and Punong-ong (1995) reported that the majority of children in the country do not progress beyond a sixth grade level of education. Additionally, more than $85 \%$ of children with disabilities are from families considered at or below the poverty level and/or from families with little or no formal education. Educational opportunities for children with disabilities may be limited due to specialized schools primarily being located in mostly metropolitan areas. These schools may offer limited opportunities for children with disabilities to interact in more inclusive settings among regular education peers. Also, parents of children with disabilities may be reluctant to send their child to a school, which can result in a child with a disability beginning school at a later age than typical peers (as cited in Carter, 2006).

Several studies found that Thai teachers in inclusive classes lack knowledge in special education, have insufficient training for teaching children with disabilities, and insufficient skills to manage the behavior of children with disabilities (Meechalard, 2003; Onbun-uea \& Morrison, 2008; Pisarnsombat, 2000; Sorathaworn, 2003; Sukkoon, 2003). One study from Surawattananun (1999) found that school principals in Bangkok agreed that inclusion was beneficial to children with autism in terms of social skills learning; however, those principals lacked knowledge and experiences to develop successful inclusion programs. Meanwhile, Indusuta (2003) found that preschool teachers in an inclusive school who have prior training or experience with children with autism have 
insufficient understanding to create assessment and evaluation instruments.

\section{Culture/Family}

The third area that impacts successful implementation of special education programs in both countries is the family and cultural beliefs about disability and the type and amount of education that is essential. In Saudi Arabia, the culture and government are linked directly to religion. The religion has an influence on the gender division in the schools, with girls and boys attending school separately. This is a possible factor in the difference in the number of girls and boys in special education programs nationally, as mentioned above. Also, it may be a factor in teachers' perspectives on inclusion. One study found male teachers were slightly less in opposition of inclusion than female teachers, possibly because of the type of education they received in their own schools (Alquraini, 2012).

Family perspectives on special education are also influential. In the institutions for students with severe disabilities, students go to school all week and visit home on weekends, meaning the families are not as involved with schoolwork. In general, families aren't typically involved with special education, even when their children are in programs that support inclusion. This makes it difficult to use their input in creating IEPs (Alquraini, 2011). A lack of involvement could also inhibit the community's involvement in reform in general.

The culture of Thailand has historically promoted mixed feelings regarding children with disabilities. The Buddhist religion in Thailand considers good and bad 
fortune in a current life to be based upon the attainment of merit through actions considered good in a previous life. This traditionally promotes a belief that knowledge is associated with age, position and current status is bestowed because of actions in a previous life (Carter, 2006). Attitudes toward children with disabilities may range from some Chinese-Thai considering a child with Down syndrome to be a sign of good luck to parents of a child with a disability considering themselves to be punished for their actions in a previous life (Fulk, Swerdlik, \& Kosuwan, 2002). Other factors that have impacted attitude toward disability are parents' level of education, socioeconomic status, and rural versus urban geographic location. In addition, because Asian culture typically does not value individualization, education in Thailand was not designed to encourage independent thinkers or support for student-centered learning (MOE, 1996). Educational reform in Thailand has struggled to keep pace with rapidly changing demands that may sometimes require changing cultural paradigms regarding perceptions of children with disabilities (Fullan, 1993; Hallinger, 1998a, b).

\section{Summary and Recommendations}

Although special education services have been expanded for children with disabilities in both countries, there are factors that continue to impact the success of inclusive programs. For example, Saudi Arabia has made great strides in its special education system since its first legislation was passed less than thirty years ago, however, it is clear that the legislation in place isn't being fully implemented by the schools. In addition, family and gender roles are prohibiting further inclusion of students as well as the creation of better IEPs for students with special 
needs. More studies within Saudi Arabia, showing the benefits of inclusion and IEPs, could aid in changing opinions on the necessity of the two tools in special education. Public campaigns addressing social and educational issues regarding students with special needs could also be beneficial, especially within the schools. On a higher level, the government should follow through with the legislation in place, requiring schools to check back programs implemented to be sure all students are truly receiving the education promised them by the laws.

In conclusion, Saudi Arabia is a leader in special education reform in the Middle East. Even so, the history of its reform is new and there is still much work to be done through government legislation. Also, for real change to be made in schools and communities, teacher and parent perspectives of individuals with disabilities need to change. At present, fewer girls than boys are enrolled in special education programs, students with severe disabilities are in separate facilities, and most students with mild disabilities are lacking IEPs and interaction with their typically developing peers. Schools need more teachers, smaller class sizes, and better testing methods. Overall, special education in Saudi Arabia is making improvements, however the provision of special education services is still a major issue.

The Thai monarch has expressed a concern to provide education for those with disabilities. It appears that governmental policies within Thailand have quickly moved toward less discriminatory education practices and are recognizing the need to educate all citizens regardless of disability. These policies promote more inclusive practices for children with disabilities in regular education programs 
as well as specialized schools providing services to children with specific disabilities. At present, the policy appears to have had different levels of implementation depending on the evaluation processes used and the individuals reporting on progress. Because Thailand is ruled by a constitutional monarchy, the tendency to criticize the government or the monarchy is greatly impeded due to fear of possible governmental reproof. Additionally, the country also struggles with limited facilities outside major cities, high poverty rates, and resistance to change in long-standing traditions.

With these difficulties to overcome, the country has made movements toward improving the quality of special education services, but needs to continue efforts to expand availability of services and ensure implementation of governmental policies. Some general strategies that could be beneficial toward the improvement of special education services could involve the development of financial incentives for special educators willing to provide services within rural/disadvantaged areas of the country. These incentives would also need to be supported by funding to improve the facilities within these rural areas which many times are extremely limited on such as textbooks and writing materials.

Furthermore, international collaborative learning programs should be created to provide opportunities for special education teachers with professional development programs. This innovative international collaborative teaching program could involve increased in-service for all teachers and training on collaborative techniques between special and regular education teachers domestically and globally. Mentoring programs could be advantageous 
toward retaining newly certified special educators. As Carter (2006) described criticism can be directed toward the effectiveness of special education services and the availability of these services, but the opportunities for children with disabilities does appear to have improved substantially over the past 20 years. The level and quality of special education services in Thailand have been well addressed in government policy and seem to be progressing toward the actualization of these policies. It would seem that progress would continue to be slow towards improving special education services within the country until government policy, provision of funding, and attitudinal change can take place.

Environmental barriers, lack of accessible transportation, services, and accommodations for individuals with disabilities continues to exist around the globe. In Thailand, monitoring of compliance with disability law and negative attitudes by service providers and society overall toward individuals with disabilities continues to impede change (Cheausuwantavee \& Cheausuwantavee, 2012). Societal perceptions hamper enforcement of law, distribution of resources, family involvement, and access to programs for students with disabilities as mandated by law (Hill \& Sukbunpant, 2013).

Disability awareness should have been promoted through government and private sectors as well as local communities across the country. With disability knowledge and understanding, disabilities are not deficits or not diseases, but just differences. People with disabilities have full potential to learn, to work, to be employed and to become productive citizens. People first language must be promoted in order to create disability 
awareness and promote inclusion. In general, Thai people have both compromising and supportive characteristics. Individuals with disabilities could be provided with the opportunity for academic and vocational training and to have the independent life living in the society. Job opportunity and creativity must be provided for people with disabilities to enter the labor market. Self-advocacy and disability movement will play the important roles to make changes in social structure and the viewers in Thailand in comparison with special/disability development and improvement among nations.

For both countries there continues to be a need to address implementation of special education legal requirements. Along with this there is a need for increased training for educators who will work with children with disabilities in inclusive settings so that they can provide the individualized education required for student success. And finally, it is essential that information is provided to citizens in both countries about the abilities of individuals with disabilities to learn and eventually succeed in life.

\section{Reference}

- Alnahdi, G. G. (2014). Special education programs for students with intellectual disability in Saudi Arabia: Issues and recommendations. Journal Of The International Association Of Special Education, 15(1), 83-91.

- Alquraini, T. (2011). Special education in Saudi Arabia: Challenges, perspectives, future possibilities. International Journal Of Special Education, 26(2), 149-159.

- Alquraini, T. A. (2012). Factors related to teachers' attitudes towards the inclusive education of students with severe intellectual disabilities in Riyadh, Saudi. Journal Of Research In 
Special Educational Needs, 12(3), 170-182. doi:10.1111/j.14713802.2012.01248.x

- Amatyakul, P., Tammasaeng, M., \& Punong-ong, P. (1995). Sectoral survey on special education in Thailand: Education for children with disabilities. Salaya, Nakorn Prathom, Thailand: Mahidol University Press.

- Carter, S. L. (2006). The development of special education services In Thailand. International Journal Of Special Education, 21(2), 32-36.

- Cheausuwantavee, T., \& Cheausuwantavee, C. (2012). Rights, equality, educational provisions and facilities for students with disabilities in Thailand: Legal and practical perspectives over the past decade. Disability, CBR, and Inclusive Development, 23(1), 71-91.

- Chonlatanon, B. (1995). Ream bot khwm tang karn suk sa pi set [The articles about special education]. Bangkok: Ministry of Education, Special Education Department.

- Driedger, D. (Ed.). (1989). The last civil right movement : Disabled peoples international. New York: St. Martins Press.

- Education System Profiles. (n.d.). Retrieved from http://www.unescobkk.org/education/resources/resources/educatio n-system-profiles/thailand/basic-education/

- Fullan, M. (1993). Change forces. London: Falmer Press.

- Fulk, B. M., \& Kosuwan, K. (2002). Special education in Thailand. Teaching Exceptional Children, 34(5), 73.

- Hallinger, P. (1998a). Educational change in Southeast Asia: The challenge of create-learning systems. Journal of Educational Administration, 36(5), 492-509.

- Hallinger, P. (1998b). Educational reform in the Asia Pacific. Journal of Educational Administration, 36(5), 417-425.

- Hill, D. A., \& Sukbunpant, S. (2013). The comparison of special education between Thailand and the United States: Inclusion and 
support for children with autism spectrum disorder. International Journal Of Special Education, 28(1), 120-134.

- Indusuta, N. (2003). A study of state and problems of the administration of joint learning for autistic child kindergartens under the office of private education commission in Bangkok metropolis. Unpublished master's thesis, Chulalongkorn University, Bangkok.

- Meechalard, J. (2003). The evaluation of teachers' potentially in mainstreaming education schools project under the jurisdiction of Bangkok metropolitan administration. Unpublished master's thesis, Rajabhat Institute Chandrakasem, Bangkok.

- MOE. (1996). Education reform at the Ministry of Education Thailand. Bangkok, Thailand: External Relations Division, Office of the Permanent Secretary, Ministry of Education.

- Office of the Permanent Secretary for Education. (2010). The education system in Thailand, Retrieved from http://www.bic. moe.go.th/th/images/stories/book/ed-eng series/6issues/edsystemnewedit.pdf

- Onbun-uea, A., \& Morrison, G. S. (2008). Educating young children with autism in inclusive classrooms in Thailand. Kasetsart Journal (Soc. Sci), 29, 268-278.

- Pisarnsombat, N. (2000). A study of state and problems of providing mainstreamed education for preschoolers in elementary schools under the Office of the National Primary Education Commission, educational region five. Unpublished master's thesis, Chulalongkorn University, Bangkok, Thailand.

- Sorathaworn, S. (2003). The study of problem and suggestion for mainstreaming between regular and special needs students in primary schools at the office of primary education at Komkean Province. Unpublished master's thesis, Konkean University, Konkean. 
- Special Needs Education in Thailand. (n.d). Retrieved from http://bangkok.angloinfo.com/information/family/schoolingeducation/special-needs/

- Sukkoon, P. (2003). Academic administration of mainstreaming schools in the office of primary education at Nakornprathom province. Unpublished master's thesis, Silapakorn University, Nakornprathom.

- Sukbunpant, S., Shirashi, E., \& Kuroda, Y. (2004). Early detection and intervention for young children with special needs in Thailand. National Institutes for Informatics Scholarly and Academic Information Navigator, 54, 1-13. Retrieved from http://ci.nii.ac.jp/naid/40007001010

- Thailand's National Education Accounts (NEA). (n.d.). Retrieved from http://www.brookings.edu/ /media/events/2013/1/25national-accounts/thai-nea.pdf

- Thirajit, W. (2000). Karn jud karn suk sa sum rub dek pi set [Education for children with special needs] (3rd ed.). Bangkok, Thailand: Chulalongkorn University Press.

- Tourism Authority of Thailand (TAT). (2015). Retrieved on May 6, 2015, from http://www.tourismthailand.org/Thailand/economy

- UNESCO International Bureau of Education. 2011. World Data on Education 2010/2011. 